\title{
ELIMINATING THE INFLUENCE OF AXLE PARAMETERS IN INFLUENCE LINE IDENTIFICATION
}

\author{
QINGQING ZHANG ${ }^{1 *}$, QIANLONG LIU1, \\ LI DAI ${ }^{2,3}$, QIANG LIU ${ }^{4}$ \\ ${ }^{1}$ School of Civil Engineering, Sichuan Agricultural University, Chengdu, China \\ ${ }^{2}$ Jiangxi Transportation Institute, Nanchang, China \\ ${ }^{3}$ Research and Development Center on Technologies and Equipment of Long- \\ Span Bridge Construction Ministry of Transport, Nanchang, China \\ ${ }^{4}$ Jiangxi Gan-E-Wan Road and Bridge Investment Co., Ltd, Nanchang, China
}

\begin{abstract}
Accurate and rapid acquisition of the strain influence line of continuous beam plays a positive role in promoting the wide application of structural health monitoring. The structural response obtained from the sensors is used to estimate the strain influence line. However, most estimation methods ignore the influence of axle parameters on the structural response, resulting in a large error in identifying the strain influence line. This paper presents a method for eliminating the influence of axle parameters of moving vehicles on strain responses to estimate the strain influence line of continuous beams based on the long-gauge strain sensing technology. By analysing the mechanical characteristics of the multi-span continuous beam, a theoretical strain influence line expression is first established to obtain the strain influence line of the continuous beam accurately. The structural response only caused by
\end{abstract}

\footnotetext{
* Corresponding author. E-mail: q.q.zhang@sicau.edu.cn

Qingqing ZHANG (ORCID ID 0000-0001-5695-8558)

Qianlong LIU (ORCID ID 0000-0002-7270-9516)

Li DAI (ORCID ID 0000-0003-3062-006X)

Qiang LIU (ORCID ID 0000-0002-8985-7961)

Copyright (C) 2021 The Author(s). Published by RTU Press
}

This is an Open Access article distributed under the terms of the Creative Commons Attribution License (http://creativecommons.org/licenses/by/4.0/), which permits unrestricted use, distribution, and reproduction in any medium, provided the original author and source are credited. 
Qingqing Zhang,

Qianlong Liv,

Li Dai, Qiang Liv

Eliminating

the Influence

of Axle Parameters

in Influence Line

Identification

\section{Introduction}

Bridge influence lines have been widely used in bridge engineering because of their intuitive, accurate, and comprehensive characteristics of reflecting structural information. The theoretical influence line (IL) is calculated based on the boundary conditions, geometric parameters, and physical parameters described in the design drawings. The real IL is extracted from the in-situ measurement, eliminating the inconsistency between the actual and design structures due to the difference in material design parameters and the uncertainty of boundary conditions.

Bridge IL has been successfully applied in many fields such as bridge weigh-in-motion, damage identification and performance evaluation (Chen et al., 2015; Hirachan \& Chajes, 2005; Liu, 2019; Štimac et al., 2011; Wang et al., 2017; Zheng et al., 2019a). There are many methods for IL estimation, which are mainly based on a mathematical algorithm, mechanical methods, vibration analysis. In terms of the mathematical method, using a single calibration truck in a probabilistic manner is proposed by using the maximum likelihood estimator principle (Ieng, 2015). Bridge IL is estimated using the adaptive B-spline basis dictionary and sparse regularisation technique (Chen et al., 2019). With the relative axle loads of trucks passing overhead, the shape of instantaneous IL is obtained through an iterative algorithm (Heitner et al., 2020). A method of identifying the stress IL is proposed by using the least-squares solution and weighted moving average (Chen et al., 2016). Big data and affine algorithms are employed to make up for the shortcomings of the IL measurement method in real bridge testing (Zhou et al., 2020). Using the cubic $B$-spline function with Tikhonov regularisation, an IL identification method is proposed based on the vehicle information and the history of the induced bridge response time of the corresponding moving vehicle for detecting structural damage (Chen et al., 2017). For the mechanical method, the IL is estimated by using strain signals induced by a single calibration truck when it passes over the sensors (OBrien et al., 2006). 
An algorithm for calibrating ILs is based on continuously measured bridge responses (strains) produced by two calibration vehicles passing across the instrumented bridge (Zhao et al., 2015). An improved theoretical IL method is proposed to obtain the structural IL from the strain measurement by adjusting the support conditions and smoothing the peak signal to fit real situations (Znidaric \& Baumgartner, 1998). An on-site calibrated IL method is proposed to identify the axle weights of moving vehicles by using the transverse distribution of wheel loads (Zhao et al., 2014). The shear IL is estimated to identify axle weights, spacing, and axle speeds using the measured shear strains near the bridge abutments (Bao et al., 2016). The dynamic IL is obtained using a semirigid simulation model of the structure verified by the field testing results (Zhao et al., 2017). By solving the motion equations of the bridge under unit force, the dynamic displacement IL under multi-axle loads is obtained by using the linear superposition principle (Wang \& $\mathrm{Qu}$, 2011). A point-by-point graphical method derives the IL (Mcnulty \& O'Brien, 2003). The analytical expression of the deflection IL is deduced by the force method to identify damage to the railway bridge (Wang et al., 2020). In vibration analysis, an appropriate method separates the fluctuation from the measured responses to estimate bridge IL with quasi-static features (Strauss et al., 2012). The dynamic fluctuation part of structural dynamic responses induced by a high-speed vehicle is eliminated based on empirical mode decomposition to obtain bridge IL (Zheng et al., 2020). Considering the effect of the random vibration of the bridge, the dynamic IL is solved by using the virtual excitation method and the vehicle-bridge coupling equation (Xu et al., 2015). In addition, the ILs are also estimated by the regularised least-squares QR decomposition, the frequency domain decomposition (Frøseth et al., 2017; Hosur \& Bhavikatti, 1996; Zheng et al., 2019a, 2019b).

Among the methods mentioned above, there are three main methods to obtain the IL of continuous beam bridges: one method is to obtain the IL by numerical simulation (Chen et al., 2019), the second method is to use a parameter to calibrate the theoretical IL (Bao et al., 2016), and the third method is to use the least square method to determine the IL (Chen et al., 2016, 2017, 2019). The first method cannot be used to master IL effectively. The second method has low precision, while the third method often represents an ill-conditioned inverse problem. Although these methods have been successfully applied in practical engineering, many issues remain to be addressed, such as lacking a clear theoretical understanding of the identified ILs and ignoring the effects of axle parameters of the test vehicles. Most IL identification methods ignore the vehicles with the same load and the same axle number. These vehicles cause different structural responses due to different axial spacing and 
axle weight ratios, especially the influence on the maximum value of the structural response. Strain influence line (SIL) estimation methods that ignore the influence of axle parameters lead to significant errors in of Axle Parameters in Influence Line identifying bridge SIL and ultimately affect the subsequent structural performance evaluation.

Traditional foil strain gauges are seen as "point" sensors and lack stability, durability, and long-term reliability, which is unsuitable for structural health monitoring. Therefore, it is impractical to employ the traditional strain sensors to monitor units and components considered possibly critical. Strain measurement using traditional strain sensors reflects local information. Fibre Bragg Grating (FBG) strain sensors are more commonly used in structural health monitoring with the advancement of fibre-optic technology. The FBG strain sensors have their outstanding advantages in many aspects such as multiplexing capabilities, high sample rate, light, and electromagnetic interference (EMI) immunity (Casas \& Cruz, 2003; Inaudi, 2001; Schulz et al., 2001; Sohn et al., 2003). Specifically, a long-gauge FBG sensor has been developed to measure the averaged strain over arbitrary gauge lengths (Li \& Wu, 2007; Zhang et al., 2018). The dynamic strain output through this novel sensor reflects local and global structural information by designing a long-gauge of the sensor, for instance, 1 2 meters. The long-gauge FBG sensors are more promising sensing alternatives for civil, structural health monitoring (SHM) systems, which were used to monitor the strain responses of the structure.

The objective of this article is to develop a method for identifying the SILs of continuous beam bridges considering the influences of axle parameters of test vehicles on strain responses. The long-gauge FBG sensing technology is used in this proposed method with its merit of measuring both local and global structural information. After that, a representation of clear expressions is established to construct theoretical SIL of continuous beams and then to identify the real SILs integrated with the correction factors estimated by eliminating the influences of axle parameters of the test vehicle on the strain response. The structure of this article is as shown below. In Section 2, the feature of long-gauge strain is introduced, and the theoretical derivation of the proposed method is provided, including the derivation of the theoretical SIL expressions, the establishment of the correction factors, and the identification of real SIL of the continuous beam bridges. Section 3 provides numerical examples verifying the feasibility of this method. Field tests description and identified results are provided in Section 4 to verify the effectiveness and robustness of the proposed method. Conclusions are drawn in Section 5. 
THE BALTIC JOURNAL

OF ROAD

AND BRIDGE

ENGINEERING

$2021 / 16(4)$

\section{Theories for strain influence line identification}

This method involves establishing the theoretical SIL expressions of continuous beams, analysing the effects of axle parameters, and estimating the real SILs. Different SIL expressions are derived using the long-gauge sensing units on the side or intermediate spans. The calibration coefficients are calculated to demonstrate the influence of the axle parameters (axle spacings and axle weight ratios) on the long-gauge strain responses. The real SILs are then obtained using the established corrector factors to calibrate the theoretical SILs.

\subsection{Long-gauge fibre optic strain sensing}

As mentioned previously, most strain sensors used for SIL identification in the literature are point-type sensors, which are too local to reveal inherent structural characteristics. In the absence of suitable sensors for area-distributed monitoring, the FBG sensors are designed with a long gauge (from $0.20 \mathrm{~m}$ to $2.00 \mathrm{~m}$ ), and the measured strain is the average strain over the long-gauge length. The long-gauge FBG sensors were used in the field test of the studied bridge because they are extended to several centimetres or meters through a particular design and manufacturing ( $\mathrm{Li} \& \mathrm{Wu}, 2007$; Zhang et al., 2018). The principal feature of the sensor is handling an embedded tube, inside which a bare optic fibre with the FBG is sleeved and fixed at two ends to ensure the measured value represents the average strain over the gauge length. The internal structure of the long-gauge FBG sensor is shown in Figure 1a. The long-gauge sensor outputs static and dynamic structural strain related to high precision structural rotations. For a beam element with two local DOF (the vertical translation $w$ and the rotation $\theta$ ) at each

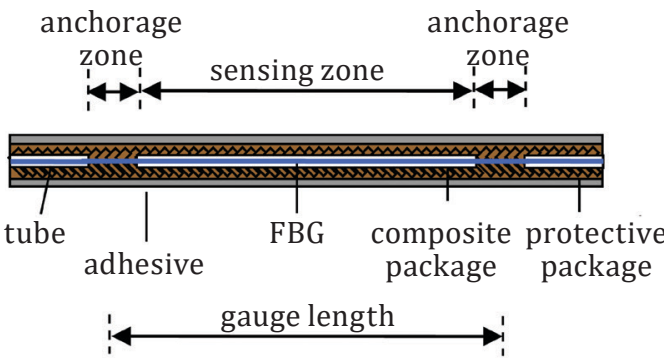

a) the internal structure

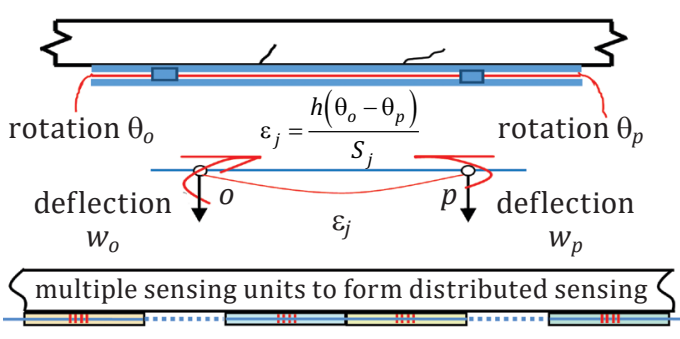

b) the measuring principle

Figure 1. The long-gauge Fiber Bragg Grating sensor 
node, the long-gauge strain (macro strain) measurement in the sensing unit is defined as follows (Equation (1)):

$$
\varepsilon_{j}(t)=\mu_{j}\left[\theta_{o}(t)-\theta_{p}(t)\right],
$$

where $\mu_{j}=h_{j} / S_{j}, h_{j}$ is the distance from the sensor to the neutral axis of the beam, $S_{j}$ is the length of the sensing unit $j ; \theta_{o}(t)$ and $\theta_{p}(t)$ are the rotations of nodes $o$ and $p$ of the sensing unit $j$ at the time, respectively. In addition, multiple sensing units are connected in a series to cover a key sensing area. Then, multiple key areas are connected to form a distributed sensing network for structural area macro-strain measuring. Figure $1 \mathrm{~b}$ demonstrates the measuring principle of the long-gauge FBG sensor.

\subsection{Establishing the mechanical expression of theoretical strain influence line}

The mechanical expression of the SIL of the continuous beam bridge is presented in this Section. For an $n$-span continuous beam, a unit on the side span is first analysed to derive the mechanical expression of the SIL. There are $(n-1)$ redundant constraints for the $n$-span continuous beam are solved by the force method. As a unit load moves along the span of the bridge, these redundant constraints are functions of the loading position $x$, which are expressed as $M_{1}(x), M_{2}(x), \ldots$ and $M_{n-1}(x)$. After releasing the redundant constraints, the SILs of the continuous beam bridge are simplified as the SILs of the simply supported beam and the response function of the monitoring unit under the action of the redundant constraints $M_{1}(x)$. So, the mechanical expressions of SIL on the first span are expressed as follows (Equation (2)):

$$
f(x)=\left\{\begin{array}{lr}
C \cdot\left\{\Omega\left(x, l_{i}\right)+R\left[M_{i}(x)\right]\right\}, & x \in L_{i}, \\
C \cdot R\left[M_{i}(x)\right], & x \in L_{j}(j \neq i)
\end{array},\right.
$$

where $C=y / E I$; $E I$ is the stiffness; $y$ is the distance from the monitoring position to the neutral axis of the beam; $\Omega\left(x, l_{i}\right)=x\left(l_{i}-x\right) / l_{i}$ represents the bending moment IL of a simply supported beam; $R\left(M_{i}(x)\right)=a M_{i}(x) / l_{i}$ is a function of the redundant constraint $M_{i}(x) ; a$ is the position of the monitoring unit on the $i^{\text {th }}$ span beam; $l_{i}$ is the length of the $i^{\text {th }}$ span of the bridge, $i=1,2, \ldots, n$; and $L_{i} \in\left(\sum_{k=0}^{i-1} l_{k}, \sum_{k=0}^{i} l_{l}\right)$. When the monitoring unit is located at the side span (i.e. the $i^{\text {th }}$ span) of the continuous beam bridge, the theoretical SIL at this unit is expressed by Equation (2). Because the SIL of the side span is different from the SIL of the intermediate span, the mechanical expression of the theoretical 
SIL is also established for the intermediate span. The theoretical SIL expressions of a unit on the $m^{\text {th }}$ span $m \neq 1, n$ of continuous beam bridge are expressed as follows (Equations (3)-(4)):

$$
\begin{gathered}
f(x)=\left\{\begin{array}{l}
C \cdot\left\{\Omega\left(x, l_{m}\right)+R^{\prime}\left[M_{m-1}(x), M_{m}(x)\right]\right\}, \quad x \in L_{m}, \\
C \cdot R^{\prime}\left[M_{m-1}(x), M_{m}(x)\right], \quad x \in L_{j}(j \neq m)^{\prime}
\end{array}\right. \\
R^{\prime}\left[M_{m-1}(x), M_{m}(x)\right]=M_{m-1}(x)+\frac{a}{l_{m}}\left[M_{m-1}(x)-M_{m}(x)\right],
\end{gathered}
$$

where $R^{\prime}$ is a function of the redundant constraint $M_{m-1}(x)$ and $M_{m}(x)$. When the monitoring unit is placed at the intermediate span (i.e., the $m^{\text {th }}$ span) of the $n$-span continuous beam bridge, the theoretical SIL of this unit is expressed by Equation (3). Based on the established Equations (2) and (3), the mechanical expressions of theoretical SIL for an $n$-span continuous beam are obtained to estimate the real SIL expressions in the field.

\subsection{Analysing the influence of axle parameters on structural response}

As shown in Figure 2, a test vehicle passes through a two-span continuous beam at a constant speed, and a unit $i$ is selected and analysed from the second span beam. The axle weight of the test vehicle with three axles is $P_{1}, P_{2}$, and $P_{3}$, respectively. The axle spacings are $d_{1}$ and $d_{2}$ between the first and second axle, and the second and third axle, respectively. The axle weight ratio for each axle is calculated with $P_{3}$ as the reference, which is $P_{1} / P_{3}, P_{2} / P_{3}$ and 1 . The axle parameters of a test vehicle mainly include the axle weight, axle spacing, and axle weight

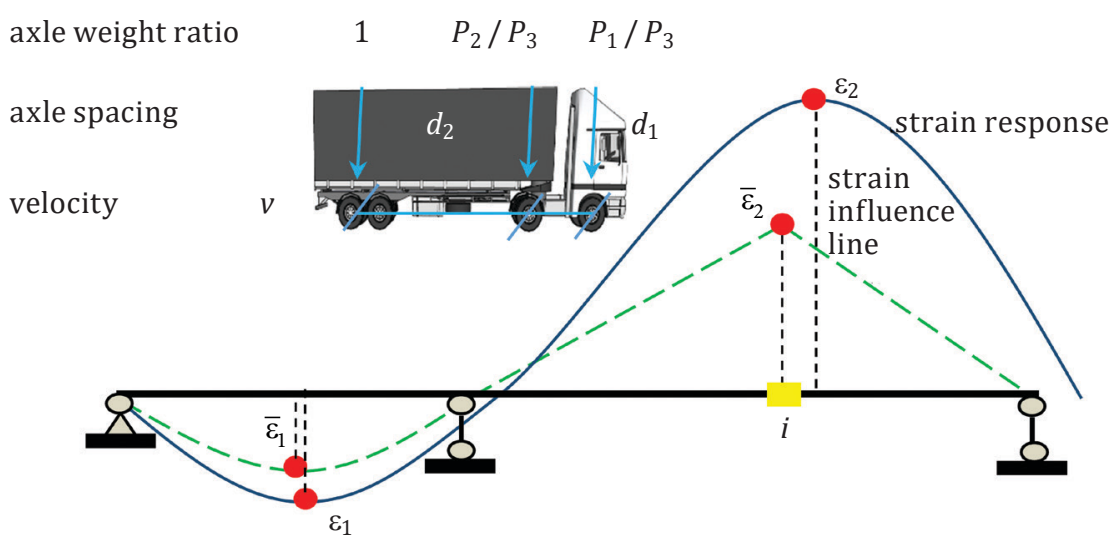

Figure 2. Strain response induced by a moving vehicle 
ratio. The relationship between the real SILs and the structural response is disproportional because of the axle spacing and axle weight ratio. It makes it challenging to correct the mechanical expression of theoretical SILs effectively. In Figure 2, the dotted line represents the SIL, while the solid line shows the strain response of unit $i$. The theoretical SIL at this unit is expressed by Equation (2). The extreme values $\bar{\varepsilon}_{1}, \bar{\varepsilon}_{2}$ and $\varepsilon_{1}, \varepsilon_{2}$ are extracted from the SIL and the strain response curves, respectively. It is seen from Figure 2 that there is nonlinear proportionality between extreme values $\bar{\varepsilon}_{1}$ and $\varepsilon_{1}$, nor between the extreme values $\bar{\varepsilon}_{2}$ and $\varepsilon_{2}$.

The structural response is caused only by the axle weights compared to the structural response under vehicle load. The extreme values found from the strain responses are extracted to evaluate the influence of axle spacings and axle weight ratios on the measured strain response. The extreme values are more accessible than the other units displayed on the strain response curve. The extreme values $\varepsilon_{1}, \varepsilon_{2}$ shown in Figure 2 are affected not only by the axle weights of the two axles but also by the axle weight ratios and the axle spacings. Because of different axle parameters, two loading models - the vehicle loading model and the axle loading model - are analysed for their extreme values. When two vehicles with the same axle weight but different axle parameters pass through the bridge, the extreme strain values extracted from the strain curves are different. Based on the establishment of theoretical SIL expressions, the strain extreme value is discussed to study the influence of the axle spacing and the axle weight ratio on the structural responses. Here, a unit at the intermediated span of the n-span continuous beam is demonstrated to analyse the extreme value from the strain responses.

A unit $k_{m}$ at the $m^{\text {th }}$ span $(m \neq 1, n)$ of an $n$-span continuous beam is analysed in this Section. Figure 3 represents the SIL and strain time history of unit km, and the strain time history is given in Figure $3 \mathrm{~b}$. Figure $3 \mathrm{c}$ is generated under the vehicle and axle loading models, respectively.

It is known from the history of strain time of the unit $k_{m}$ that there are $n$ extremes on the curve, expressed as $\varepsilon_{1}, \varepsilon_{2}, \ldots, \varepsilon_{m}, \ldots, \varepsilon_{n}$, as shown in Figure $3 \mathrm{~b}$. A group of vehicles with $n_{a}$ axles pass across the investigated bridge. When the $n_{i}^{\text {th }}$ axle acts at the unit $k_{m}$, the maximum value $\varepsilon_{m}$ on the strain-time history occurs and is expressed as follows (Equations (5)-(8)):

$$
\begin{gathered}
\varepsilon_{m}=\frac{C_{m}^{\prime}}{l_{m}}\left(\Psi_{m}^{1}-\Psi_{m}^{2}+\Psi_{m}^{3}\right), \\
\Psi_{m}^{1}=\sum_{j=1}^{n_{a}} P_{j} X_{m}\left(l_{m}-x_{m}\right),
\end{gathered}
$$

Eliminating the Influence of Axle Parameters in Influence Line Identification 


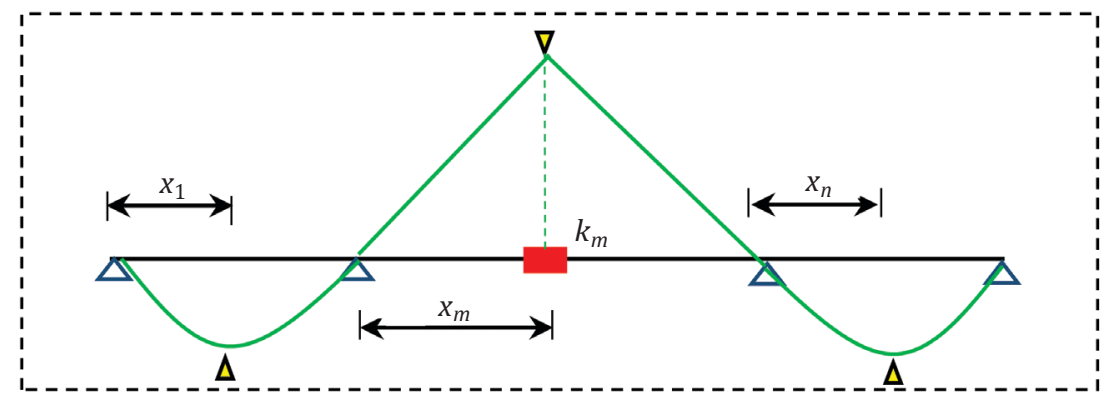

a) strain influence line of unit $k_{m}$

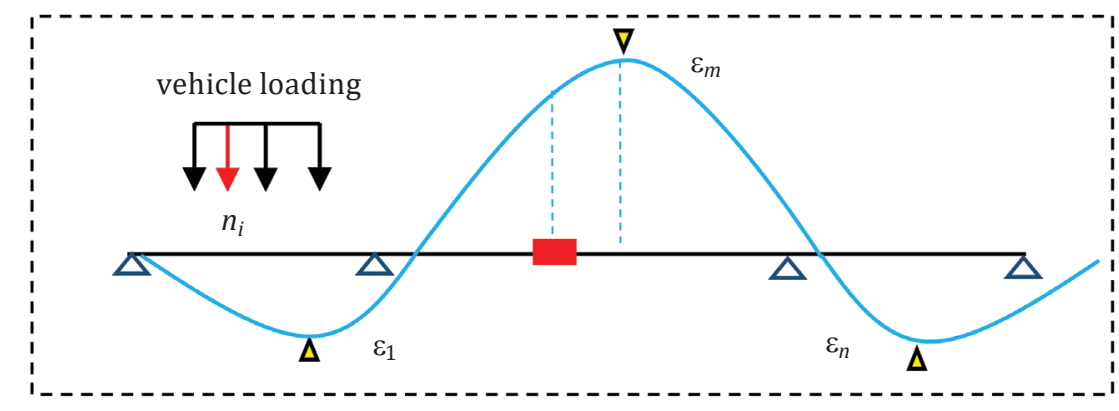

b) strain response of the unit $k_{m}$ under the vehicle load model

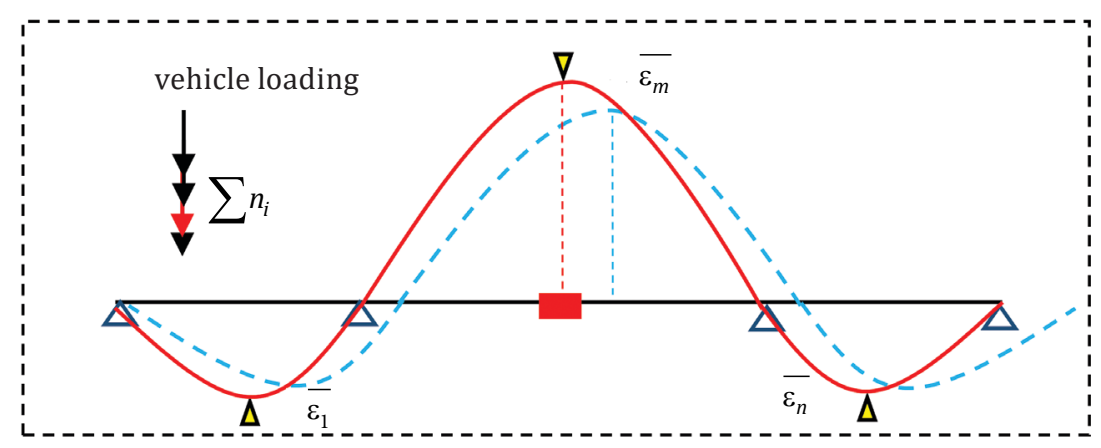

c) strain response of the unit $k_{m}$ under the axle load model

Figure 3. Analysis of the structural responses induced by different loading models 


$$
\begin{aligned}
& \Psi_{m}^{2}=\sum_{\delta=1}^{n_{i-1}} \sum_{j=1}^{\delta} P_{j} d_{\delta} x_{m}+\sum_{\delta=n_{i+1}}^{n_{a}} \sum_{j=\delta}^{n_{a}} P_{j} d_{\delta-1}\left(l_{m}-x_{m}\right), \\
& \Psi_{m}^{3}=l_{m}\left\{\begin{array}{l}
\sum_{j=1}^{n_{i-1}} P_{j} \Omega\left[X_{m-1}\left(\beta_{m}\right), X_{m}\left(\beta_{m}\right)\right]+P_{n_{i}} \Omega\left(x_{m}\right)+ \\
\sum_{j=n_{i+1}}^{n_{a}} P_{j} \Omega\left[X_{m-1}\left(\beta_{m}\right), X_{m}\left(\beta_{m}\right)\right]
\end{array}\right\},
\end{aligned}
$$

where $\beta_{m}$ in Equation (8) is a function of $x_{m}$ and is expressed as follows (Equation (9)):

$$
\beta_{m}=x_{m}+\sum_{\alpha=j}^{n_{i-1}} d_{\alpha} .
$$

In Equation (6), $\Psi_{m}^{1}$ is the partial response only caused by the axle weights; $\Psi_{m}^{2}$ is mainly caused by the axle spacing and the axle weight ratio, as shown in Equation (7); $\Psi_{m}^{3}$ is mainly caused by two redundant constraints, as shown in Equation (8). In Figure 3c, the maximum strain $\overline{\varepsilon_{k_{m}, m}}$ is only caused by the axle weights and is then expressed in Equations (10) and (11).

$$
\begin{gathered}
\overline{\varepsilon_{m}}=\frac{C}{l_{m}} \overline{\Psi_{m}}, \\
\overline{\Psi_{m}}=\sum_{j=1}^{n_{a}} P_{j} x_{m}\left[l_{m}-x_{m}+\Omega\left(x_{m}\right)\right],
\end{gathered}
$$

The calibration coefficient $r_{m, m}$ for the $m^{\text {th }}$ extreme unit is calculated by dividing Equation (5) by Equation (10) and shown in Equation (12).

$$
r_{m, x_{m}}=\frac{\varepsilon_{m}}{\overline{\varepsilon_{m}}}=\frac{C_{m}^{\prime}}{C} \varphi_{m}=\frac{C_{m}^{\prime}}{C}\left(\frac{\Psi_{m}^{1}}{\overline{\Psi_{m}}}-\frac{\Psi_{m}^{2}}{\overline{\Psi_{m}}}+\frac{\Psi_{m}^{3}}{\overline{\Psi_{m}}}\right)
$$

In the same way, it is assumed that when the $n_{i}^{\text {th }}$ axle acts on the $\zeta^{\text {th }}$ extreme unit of the theoretical SIL, the $\zeta^{\text {th }}(\zeta \neq m)$ extreme value occurs on the measured strain-time history curve and is expressed as follows (Equations (13)-(14)):

$$
\varepsilon_{\zeta}=\frac{C_{\zeta}^{\prime}}{l_{\zeta}} \Psi_{\zeta}
$$




$$
\Psi_{\zeta}=l_{m}\left\{\begin{array}{l}
\sum_{j=1}^{n_{i-1}} P_{j} \Omega\left[X_{\zeta-1}\left(\beta_{\zeta}\right), X_{\zeta}\left({ }_{\zeta}\right)\right]+P_{n_{i}} \Omega\left(x_{\zeta}\right)+ \\
\sum_{j=n_{i+1}}^{n_{a}} P_{j} \Omega\left[X_{\zeta-1}\left(\beta_{\zeta}\right), X_{\zeta}\left(\beta_{\zeta}\right)\right]
\end{array}\right\} .
$$

The $\zeta^{\text {th }}$ extreme value $\overline{\varepsilon_{\zeta}}$ caused only by the axle weights are calculated and expressed as follows (Equation (15)):

$$
\overline{\varepsilon_{\zeta}}=\frac{C}{l_{\zeta}} \sum_{j=1}^{n_{a}} P_{j} \Omega\left(\xi_{\zeta}\right) .
$$

So the calibration coefficient $r_{\zeta, \zeta}$ for the $\zeta^{\text {th }}$ extreme value of the unit $k_{m}$ is described by Equation (16).

$$
r_{\zeta}, x_{\zeta}=\frac{\varepsilon_{\zeta}}{\overline{\varepsilon_{\zeta}}}=\frac{C_{\zeta}^{\prime}}{C} \varphi_{\zeta}=\frac{C_{\zeta}^{\prime}}{C}\left(\frac{\Psi_{\zeta}}{\sum_{j=1}^{n_{a}} P_{j} \Omega\left(x_{\zeta}\right)}\right)
$$

It is seen from the established Equations (11) and (15) that the calibration coefficient $r$ is mainly composed of two parts. The first part of $r$ is the ratio between the actual and theoretical strain coefficients. Moreover, the second part of $r$ is a ratio of bending moment responses calculated by all axle parameters and only by the axle weights. The second part $\varphi$ of Equations (12) and (16) demonstrates the influence of axle spacing and axle weight ratio on the strain responses.

\subsection{Eliminating the influence of axle parameters to identify strain influence line}

The difference between the theoretical SIL and the real SIL is the different coefficients in the SIL expressions. To obtain the real SILs of an n-span continuous beam, the ratio between the actual coefficients $C^{\prime}$ and the theoretical strain coefficients $C$ needs to be calculated. Equations (11) and (15) provide only the calibration coefficients of $n$ extreme units on the theoretical SIL. Each calibration coefficient is then calculated with $(=0)$ at two bearings to obtain the calibration coefficients matrix $r$ in a span beam. $r=\left[r_{1} r_{2} \cdots r_{m} \cdots r_{n}\right]^{T}$, and $r_{m}=\left[0 r_{m, 1} r_{m, 2} \cdots r_{m, x_{m}} \cdots r_{m, l_{n-1}} 0\right]$. Based on the effects of axle parameters, the calibration coefficients matrix $r$ is directly calculated by the measured extreme values and the simulated extreme values based on the IL theory. The coefficient $\varphi$ is estimated from the derived related expression. Thus, the first part of Equations (11) and (15) as the correction factors $r c$ are expressed as follows (Equation (17)): 


$$
r c_{i, \varrho}=\frac{C_{i}^{\prime}}{C}=\frac{r_{i, j}}{\varphi_{i}}, i=1,2, \cdots, n ; \varrho=1,2, \cdots l_{i} .
$$

The calibrated SILs at the unit $k_{m}$ on the intermediate span is calculated by substituting Equation (17) into Equation (3) and is expressed as follows (Equation (18)):

$$
F(x)=\left\{\begin{array}{lr}
r c_{m, \varrho} C \cdot\left\{\Omega\left(x, l_{m}\right)+R^{\prime}\left[M_{m-1}(x), M_{m}(x)\right]\right\}, & x \in L_{m} \\
r c_{j, \varrho} C \cdot R^{\prime}\left[M_{m-1}(x), M_{m}(x)\right], & x \in L_{j}(j \neq m)
\end{array} .\right.
$$

The real SILs of unit $k_{1}$ on the side, span are also obtained based on the calibrated method of the theoretical SILs mentioned above. When the bridge is considered a two-dimensional model, Equation (8) is enough to obtain the real SILs. However, when the bridge is simulated as a threedimensional model, the effect of the transverse position of vehicle load needs to be analysed on Equation (8). Figure 4 shows the monitoring unit with different lane distributions, and the red rectangular block represents the monitoring location. A case given in Figure 4a demonstrates the monitoring unit facing a lane. Figure $4 \mathrm{~b}$ shows the monitoring unit deviating from the lane.

The calibrated SILs are obtained using Equation (18) if a lane corresponds to the monitoring unit. So, Equation (8) is applicable for the case from Figure 4 a to estimate the SILs. However, if the monitoring unit deviates from the lane centreline, it is challenging to use Equation (18) to estimate the SILs directly. For the case from Figure 4b, two or more lanes are found that deviate from the monitoring unit. Here, strain responses collected from two lanes closest to the monitoring unit is used to estimate $\varepsilon_{\zeta}$ in Equation (16), as shown in Figure 5. When a calibration vehicle with load $P$ passes on a lane $l_{a_{1}}$ and lane $l_{a_{j}}$ respectively, the strain responses of the monitoring unit are collected by the sensors, and then the corresponding extreme value $\varepsilon_{\zeta, l_{a_{i}}}$ and $\varepsilon_{\zeta, l_{a_{j}}}$ are extracted from the collected strain responses. Using the linear interpolation method, $\varepsilon_{\zeta}$ is expressed as (Equation (19)):

$$
\varepsilon_{\zeta}=\frac{\varepsilon_{\zeta, l_{a_{i}}} y_{l_{a_{i}}}+\varepsilon_{\zeta, l_{a_{j}}} y_{l_{a_{j}}}}{y_{l_{a_{i}}}+y_{l_{a_{j}}}}
$$

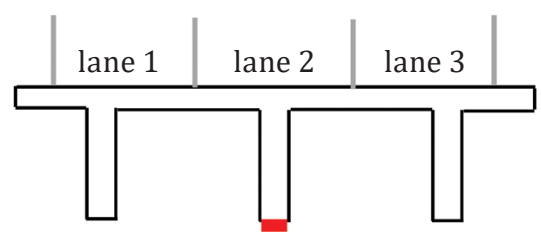

a) facing lane

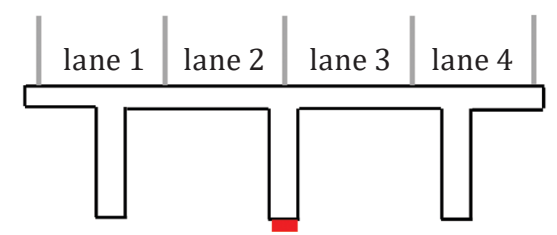

b) off lane

Figure 4. Monitoring unit with different lane distribution 


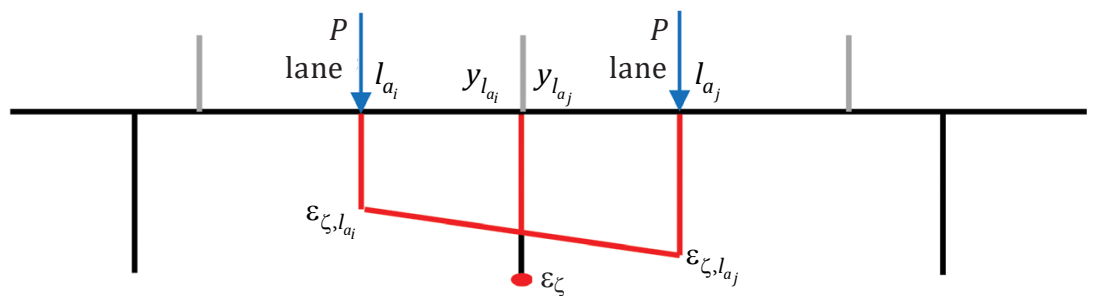

Figure 5. Calculation principle of the extreme value $\varepsilon_{\zeta}$

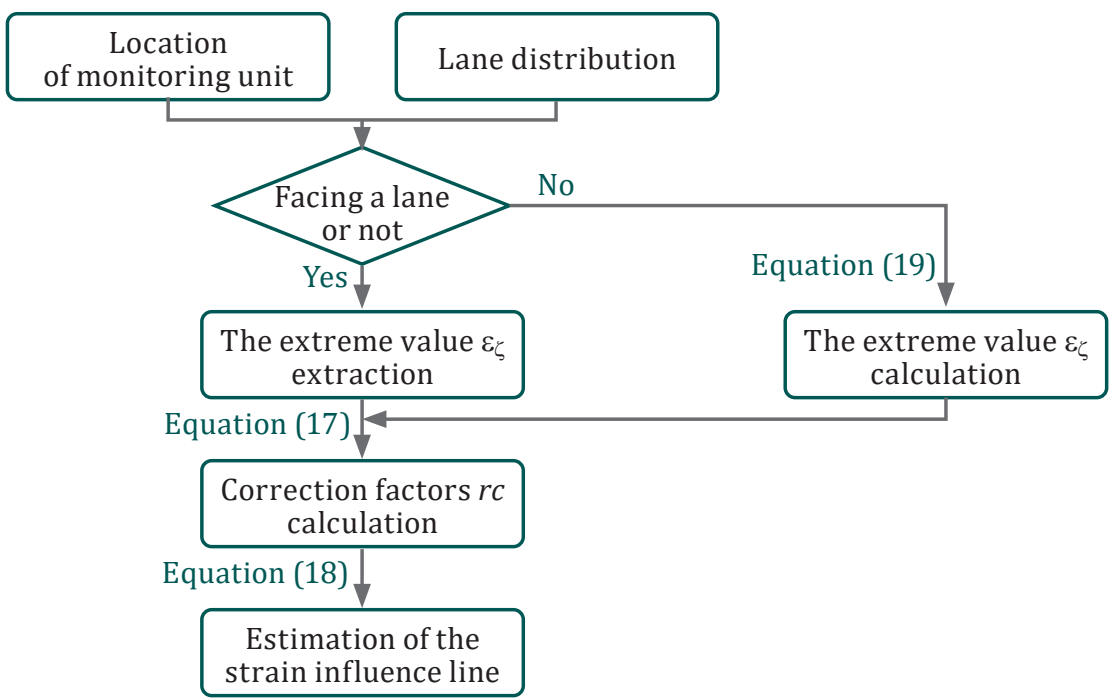

Figure 6. A flow chart of the proposed algorithm

To further illustrate the proposed algorithm, a flow chart describing the procedure of this algorithm is given in Figure 6.

\section{Numerical verification}

\subsection{Theoretical strain influence line estimation}

The proposed method for identifying the SIL of the continuous beam described in Section 2 is proven here using a numerical example. The investigated structure is a pre-stressed concrete continuous box-girder bridge of four spans with a total of $120.0 \mathrm{~m}$. The length of each span beam is $30.0 \mathrm{~m}$. A single-case single-compartment section is used in this beam, and its height and width are $1.5 \mathrm{~m}$ and $12.5 \mathrm{~m}$, respectively. 
Each span beam of the bridge is divided into 15 units, and every unit is $2.0 \mathrm{~m}$ in length. This Section first verifies the derived theoretical of Axle Parameters in Influence Line SIL expressions by comparing SIL at different speeds using the finite Identification element method (FEM). Here the unit load is approximately simulated as a triangular load applied to each node. The truckload is simulated, and each axle load is set to a triangular load and applied to the bridge node. When a unit load passes over the investigated bridge at a speed of $30 \mathrm{~km} / \mathrm{h}, 50 \mathrm{~km} / \mathrm{h}$, and $80 \mathrm{~km} / \mathrm{h}$, the strain at the bottom of the units $x_{k_{1}}, x_{k_{2}}, x_{k_{3}}$, and $x_{k_{4}}$ are collected and extracted, respectively, to verify the effectiveness of the theoretical SILs. These vehicle loads are applied to the lane facing the monitoring unit. Units $x_{k_{1}}, x_{k_{2}}, x_{k_{3}}$, and $x_{k_{4}}$ are the midpoints of each span beam.

Figure 7 shows four SIL diagrams corresponding to the four monitoring units along the investigated continuous beam. It is easy to see that the calculated SILs are close to those obtained with FEM. At different speeds, the theoretical SIL extracted from the FEM is consistent with the SIL calculated by the proposed theoretical expressions, although it shows different degrees of curve fluctuation. Figure 7 also indicates that the dynamic SIL extracted at different speeds is the
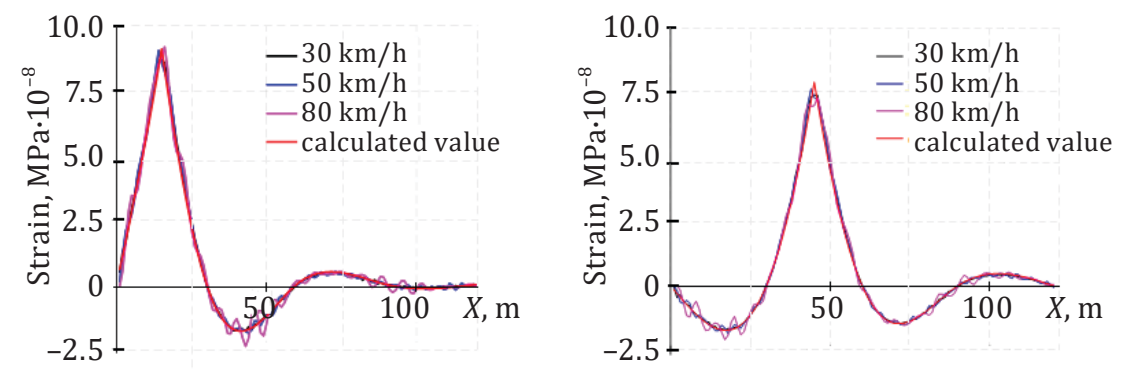

a) $x_{k 1}$

$$
\text { b) } x_{k_{2}}
$$
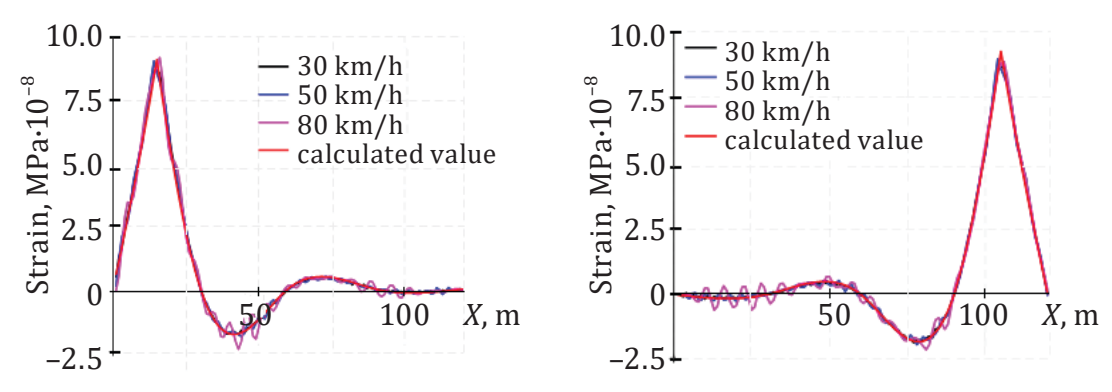

c) $x_{k 3}$

d) $x_{k 4}$

Figure 7. Calculated theoretical strain influence lines based on the proposed method 
THE BALTIC JOURNAL OF ROAD AND BRIDGE ENGINEERING 2021/16(4)

same as the static SIL. The formulation is given in Equation (9) for the theoretical SIL remains valid even at different speeds of a unit load.

\subsection{Strain influence line calibration}

In this Section, parametric sensitivity analysis is conducted using the proposed method of SIL identification, which considers the effects of different axle parameters. Parameters selected for sensitivity analysis mainly include the axle spacings, axle weight ratios, and axle velocity.

\subsubsection{Axle parameters}

The analysed axle parameters of test vehicles included axle spacings and axle weight ratios. Two two-axle trucks that pass across the four-span continuous beam bridges in the calibration test are studied to demonstrate the influences of the axle parameters on the strain responses. The two trucks (truck I and truck II) have the same total weight of $200 \mathrm{kN}$ and pass across the continuous beam bridge at the same speed of $30 \mathrm{~km} / \mathrm{h}$. For truck I, the weights of the front and rear axles are $50 \mathrm{kN}$ and $150 \mathrm{kN}$ (axle weight ratios are 0.33 and 1), respectively, and the axle spacing between the front and rear axles is $6.5 \mathrm{~m}$. For truck II, the weights of the front and rear axles are $75 \mathrm{kN}$ and $125 \mathrm{kN}$ (axle weight ratios are 0.6 and 1), respectively, and the axle spacing between the front and rear axles is $4.5 \mathrm{~m}$. Five per cent of white noise is added to the extracted strain response data to consider the noise level.

Figure 8 represents the strain time history curves of the four monitoring units when trucks I and II pass across the bridge. Although the total weight of the two trucks is the same, the difference in axle spacing and the axle weight ratios results in different strain extreme values and occurrence positions for each monitoring unit, and the

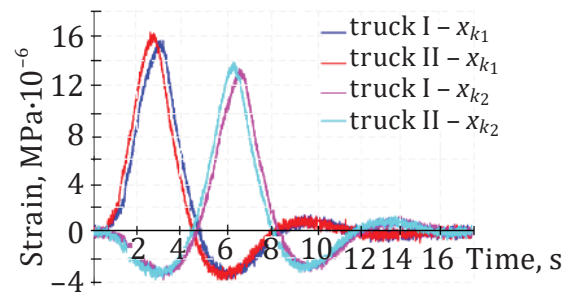

a) $x_{k_{1}}$ and $x_{k_{2}}$

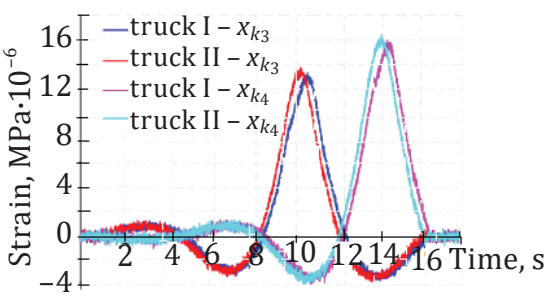

b) $x_{k_{3}}$ and $x_{k_{4}}$

Figure 8. Strain time histories induced by the two trucks 
maximum strain of each curve is undeniable. In Figure 8a, the strain curves of the $x_{k_{1}}$ truck I and truck II are inconsistent, and the occurrence of Axle Parameters in Influence Line time and the maximum strain value are different. The strain curves of Identification $x_{k_{2}}, x_{k_{3}}$, and $x_{k_{4}}$ are shown in Figures $8 \mathrm{a}$ and $8 \mathrm{~b}$ show similar differences.

The coefficient $\varphi$ was first calculated and analysed using Equations (12), (16), as shown in Figure 9a, to observe the sensitivity of axle spacing and axle weight ratio parameters. Four extreme values are found for a monitoring unit on the four-span continuous beam, so there are sixteen coefficients $\varphi$ for truck I and truck II. The extreme points $1,6,11$, and 16 shown in Figure 9a are the maximum values of strain time histories of $x_{k_{1}}, x_{k_{2}}, x_{k_{3}}$, and $x_{k_{4}}$, respectively, and the differences at these extreme points are minor among the two cases. All calculated coefficients $\varphi$, except at the four extreme points mentioned above for truck I, are significantly above the corresponding coefficients $\varphi$ obtained for truck II, confirming that the different axle parameters have a noticeable effect on the strain responses. The correction factors to calibrate the theoretical SIL are estimated based on Equation (17), as shown in Figure 9b. Since the FEM adopted is an ideal model, each correction factor in the theoretical SIL formula equals 1 . The extreme points, such as extreme points 4, 8, 9, and 12 shown in Figure 9b, are far away from the monitoring unit and are close to zero, leading to significant errors in calculating their correction factors.

After removing the correction factors corresponding to the above extreme values close to zero, the absolute mean error of all correction factors for each monitoring unit is calculated for trucks I and II, respectively, as shown in Figure 10. It is seen from Figure 10 that the error of the correction factor of the $x_{k_{4}}$ is more significant than other units, which is $3.52 \%$ for truck I and $3.29 \%$ for truck II.

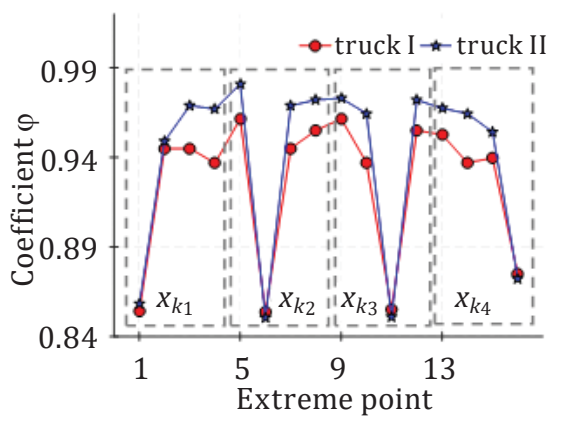

a) coefficient $\varphi$

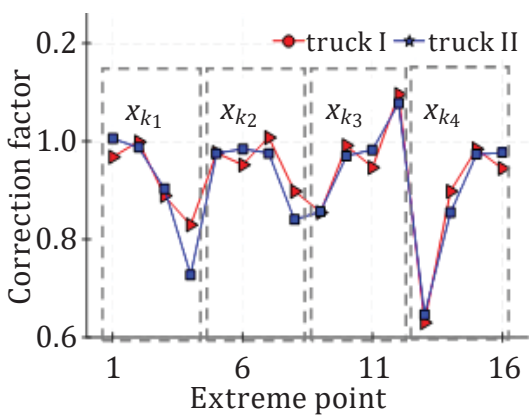

b) correction factor

Figure 9. Comparative analysis of different axle parameters 
When ignoring the influence of axle spacings and axle weight ratio on the structural response, modifying the theoretical SIL is compared to the proposed method by calculating the correction factor, as shown in Figure 11. The theoretical SILs of the units $x_{k_{1}}, x_{k_{2}}, x_{k_{3}}$, and $x_{k_{4}}$, and the SILs calibrated using the proposed method and the method of ignoring the axle parameters are shown in Figures 11a-11d. For truck I, SILs identified using the proposed method and matching the actual SILs.

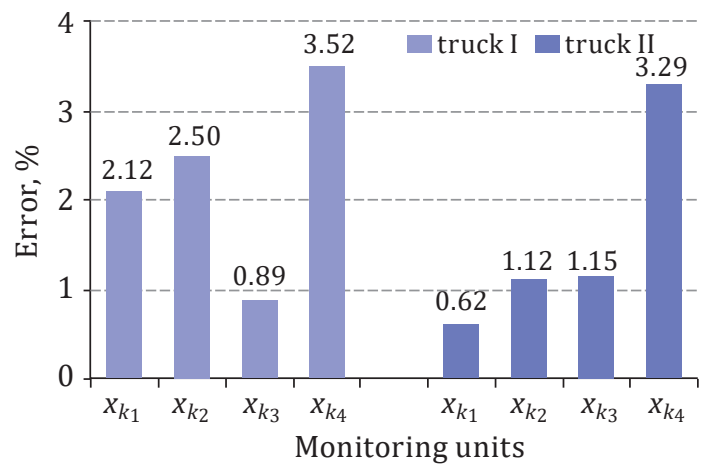

Figure 10. The error of the calculated correction factor
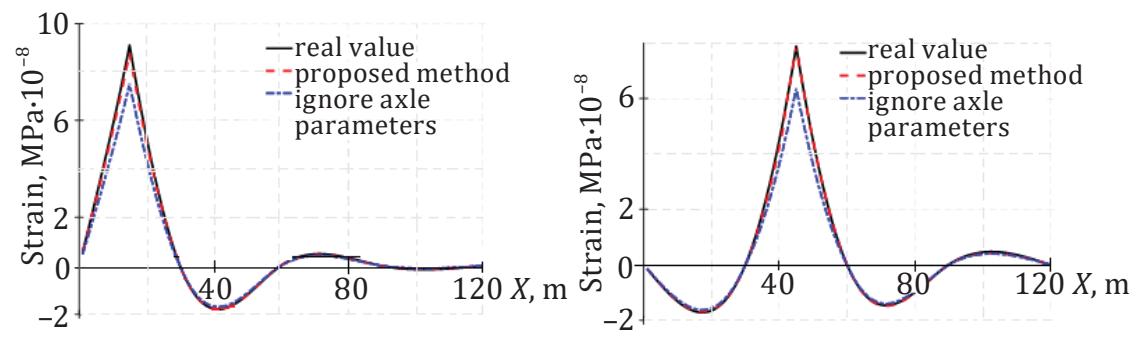

a) $x_{k_{1}}$

b) $x_{k 2}$
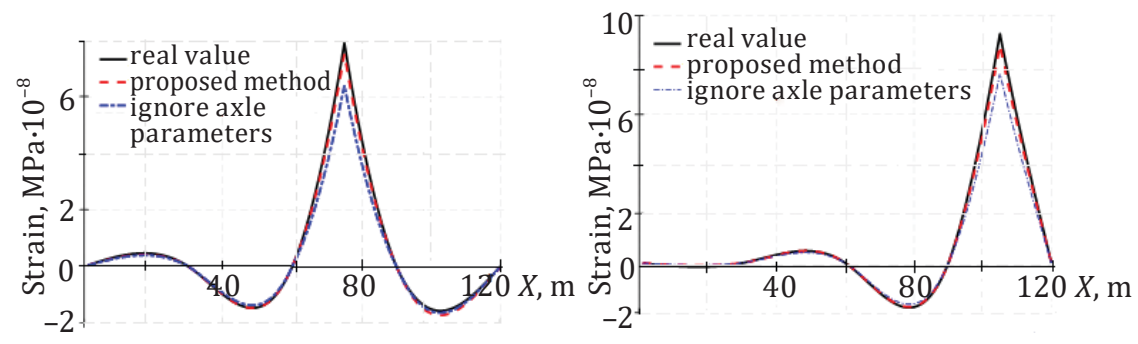

c) $x_{k 3}$

d) $x_{k 4}$

Figure 11. Comparison of the calibrated strain influence line and the theoretical curve for the truck I 
However, the SIL modified by the method ignores the axle parameters that differ significantly from the authentic SIL at the maximum value. So it is concluded that the proposed method effectively eliminate the influence of different axle parameters on the calibrated SIL.

\subsubsection{Different speed testing}

The dynamic responses of the continuous beam bridge to the passage of a three-axis truck at $30 \mathrm{~km} / \mathrm{h}, 50 \mathrm{~km} / \mathrm{h}$, and $80 \mathrm{~km} / \mathrm{h}$ are studied. The total weight of the test truck is $420 \mathrm{kN}$. The axle weights of the front, middle and rear axles are $60 \mathrm{kN}, 120 \mathrm{kN}$, and $240 \mathrm{kN}$, respectively. The spacing between the axles is $3.5 \mathrm{~m}$ and $7.8 \mathrm{~m}$, respectively. Noise levels of $2 \%, 5 \%$, and $10 \%$ are considered at the speeds of $30 \mathrm{~km} / \mathrm{h}, 50 \mathrm{~km} / \mathrm{h}$, and $80 \mathrm{~km} / \mathrm{h}$, respectively.

The strain responses of $x_{k_{1}}, x_{k_{2}}, x_{k_{3}}$, and $x_{k_{4}}$ are collected and used to calibrate the SIL at different vehicle speeds. Figures $12 \mathrm{a}$ and $12 \mathrm{~b}$ represent the strain time history curves of unit $x_{k_{1}}$ and $x_{k_{2}}$ under the cases of the vehicle speeds of $30 \mathrm{~km} / \mathrm{h}, 50 \mathrm{~km} / \mathrm{h}$, and $80 \mathrm{~km} / \mathrm{h}$, respectively. It is evident from Figure 12 that the higher the vehicle speed, the greater the fluctuation in the structural response curve, especially the response around the extreme, but the extreme points on each strain curve are unaffected by the vehicle speed and are extracted stably from the strain responses.

The coefficients $\varphi$ of each extreme point were calculated (Figure 13a). Sixteen extreme values correspond to the four monitoring units $x_{k_{1}}, x_{k_{2}}, x_{k_{3}}$, and $x_{k_{4}}$. It is evident from Figure 10 that the calculated coefficients $\varphi$ at the same extreme point are identical at different speeds, except for those points where the extreme values are close to zero. The correction factors are further estimated using the calculated coefficients $\varphi$ (Equation (17), Figure 13b). Some extreme points, such as extreme points $4,8,9$, and 12 shown in Figure 13b, are far away from the monitoring unit and close to zero leading to significant errors in

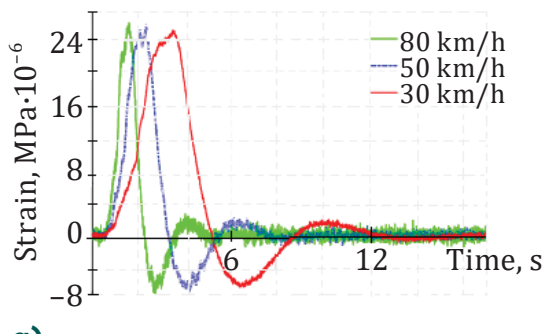

a) $x_{k 1}$

b) $x_{k_{2}}$

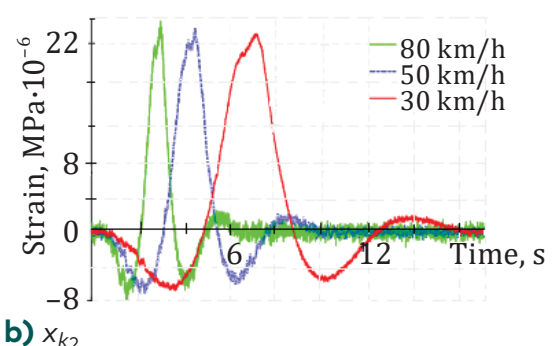

Figure 12. Strain time history for different velocities
Eliminating the Influence of Axle Parameters in Influence Line Identification 
calculating their correction factors. In addition, the correction factors at most of the extreme points fluctuate around 1.

The mean error of all correction factors for monitoring units $x_{k_{1}}$, $x_{k_{2}}, x_{k_{3}}$, and $x_{k_{4}}$ is calculated by removing the correction factors at the extreme points, for which extreme values are close to zero, as shown in Figure 14. It is evident from Figure 14 that the maximum error of the corrector factor occurs at the monitoring unit $x_{k_{3}}$ at the speed of $80 \mathrm{~km} / \mathrm{h}$, and the error is $4.24 \%$. The corrector factors calculated by the proposed method are practical, and the different vehicle velocities have little affection on the corrector factors.

The theoretical SILs of the units $x_{k_{1}}, x_{k_{2}}, x_{k_{3}}$, and $x_{k_{4}}$ and the SILs calibrated using the proposed method and the method that ignores axle parameters are shown in Figure 15. The method of ignoring axle parameters use the extreme value from strain response directly to modify the theoretical SIL for obtaining the authentic SIL. For different

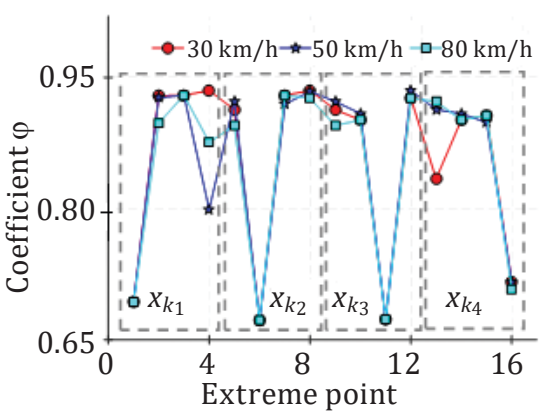

a) coefficient $\varphi$

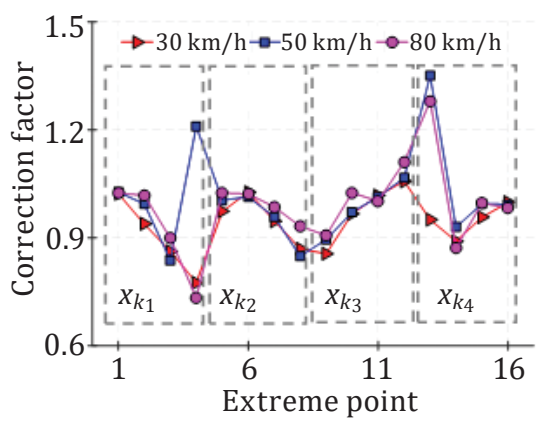

b) correction factor

Figure 13. Comparative analysis of different vehicle velocities

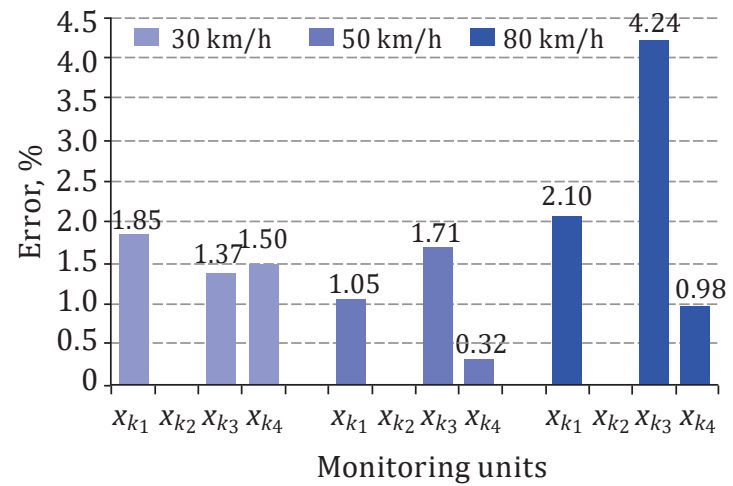

Figure 14. The error of the calculated correction factor 
vehicle velocities, the SILs identified by the proposed method are consistent with the actual SILs. However, there are apparent differences of Axle Parameters in Influence Line between the real SILs and the SILs estimated using the method that Identification
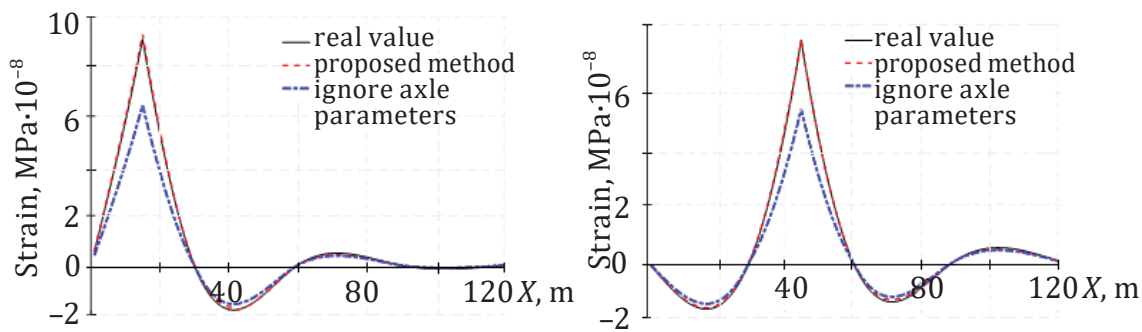

a) $x_{k_{1}}-30 \mathrm{~km} / \mathrm{h}$

b) $x_{k_{2}}-30 \mathrm{~km} / \mathrm{h}$
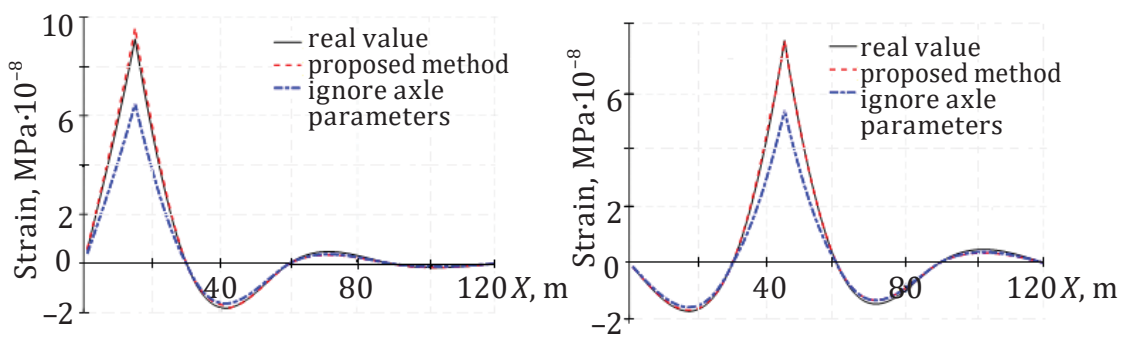

c) $x_{k 1}-50 \mathrm{~km} / \mathrm{h}$

d) $x_{k_{2}}-50 \mathrm{~km} / \mathrm{h}$
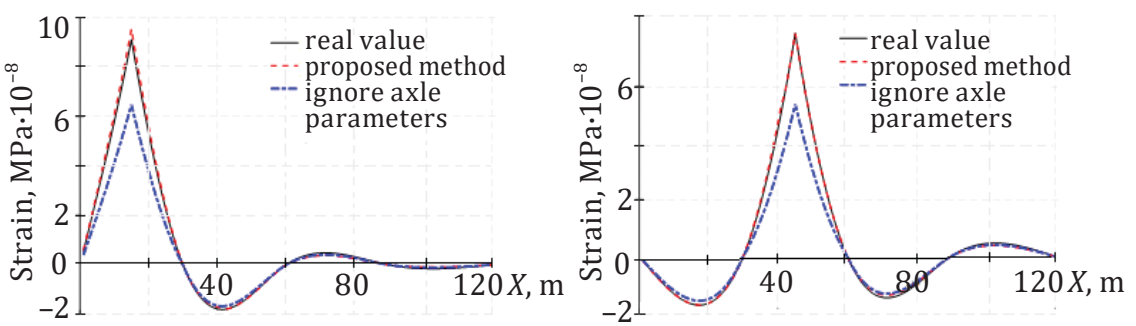

e) $x_{k 1}-80 \mathrm{~km} / \mathrm{h}$

f) $x_{k_{2}}-80 \mathrm{~km} / \mathrm{h}$

Figure 15. Comparison of modified strain influence line and the theoretical curve in different cases 
(Figures 15c and 15e). So it is concluded that at low vehicle speeds, the SILs are identified effectively using the proposed method. Although higher speeds have a particular impact on the extreme values of SIL, the identified accuracy is generally within the acceptable range, which is mainly due to the fluctuation of the maximum values.

\subsubsection{Different lane testing}

Two lanes with a width of $3.75 \mathrm{~m}$ are simulated for vehicle testing to investigate the effect of different lane testing on the proposed SIL method (Figure 16). Figures 16a and 16b show two different lane testing cases. Case I employs two lanes at both sides of the road centre line, respectively, while the two lanes in Figures 16a are shifted by $1 \mathrm{~m}$ to the left in case II. For each case, the above test vehicle is used to pass through the two lanes at a speed of $80 \mathrm{~km} / \mathrm{h}$, and the response data of the monitoring units were collected. Noise levels of $5 \%$ are considered in the two test cases, respectively. With the proposed method, SIL is calculated for each monitoring unit and compared to the calculation method that ignores the axis parameters, and the identification results are shown in Figure 17.

Figures $17 \mathrm{a}$ and $17 \mathrm{~b}$ show the identified SIL of $x_{k_{1}}$ and $x_{k_{2}}$ respectively under case I, and Figures 17c and 17d give the results of $x_{k_{1}}$ and $x_{k_{2}}$ under case II. For different lane testing cases, the SILs identified by the proposed method are consistent with the actual SILs. However, there are apparent differences between the real SILs and the SILs estimated using the method that ignores axle parameters. In Figures 17a and 17b, the errors of the maximum value between the SIL identified with the proposed method and the authentic SIL is $4.9 \%$ and $0.5 \%$, respectively. In Figures $17 \mathrm{c}$ and $17 \mathrm{~d}$, the errors of the maximum value between the SIL identified with the proposed method and the authentic SIL is 5.0\% and $0.5 \%$, respectively. So it is concluded that the SILs are identified effectively using the proposed method for the test lanes shown in Figure 16. The above analysis shows that the proposed method in this paper

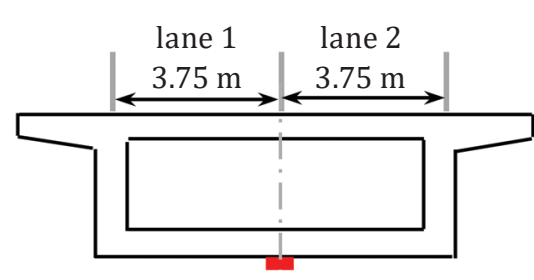

a) case I

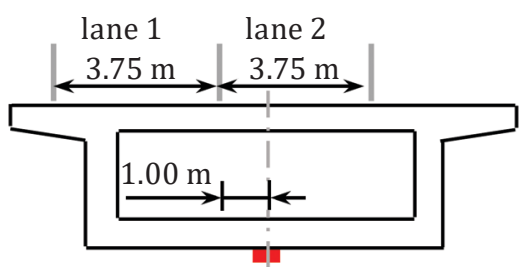

b) case II

Figure 16. Different lane testing cases 
obtains effective SIL regardless of whether the monitoring unit has a

\section{Verification using field-test data}

\subsection{Description}

The structure investigated in this study was a pre-stressed concrete continuous box-girder bridge of three spans with a total length of $191.00 \mathrm{~m}$ (Figures 18a and 18b). The side span length was $53.00 \mathrm{~m}$, and the midspan length was $85.00 \mathrm{~m}$. The height of its main span box girder ranged from $2.40 \mathrm{~m}$ at mid-span to $5.00 \mathrm{~m}$ at the central pier with a second-order parabolic law. The widths of the top and the bottom plates of the typical cross-section at the centre of the girder were $17.25 \mathrm{~m}$ and $8.80 \mathrm{~m}$, respectively. As shown in Figure 13, three long-gauge FBG strain sensors with a gauge length of $1.00 \mathrm{~m}$ were installed on the bottom plate of the concrete box-girder to measure structural strain responses, the monitoring position on the cross-section shown in Figure 18c. The sampling frequency of the field testing was set at $500 \mathrm{~Hz}$. One
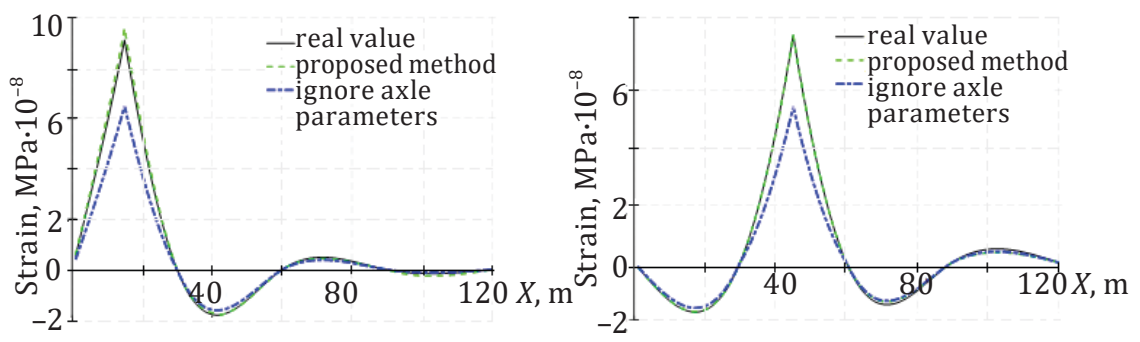

a) $x_{k_{1}}-$ case 1

b) $x_{k_{2}}-$ case 1
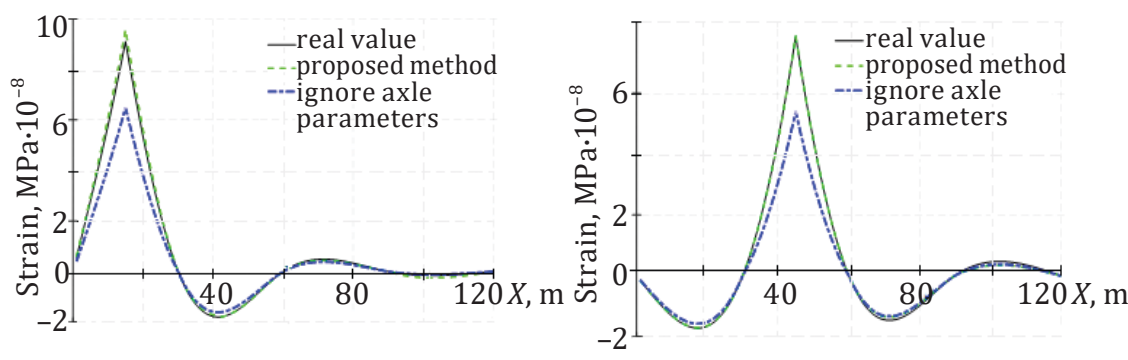

c) $x_{k 1}$ - case II

d) $x_{k_{2}}-$ case II

Figure 17. Comparison of modified strain influence line and the theoretical curve for different lane testing 
pre-weighed truck with a gross weight of $300 \mathrm{kN}$ was adopted for the field test, in which it crossed over the continuous girder bridge at a low speed of approximately $5 \mathrm{~km} / \mathrm{h}$. The test truck acted on the lane facing the monitoring units. The weights of the front, middle and rear axles of the truck were $60 \mathrm{kN}, 120 \mathrm{kN}$, and $120 \mathrm{kN}$, respectively, and the spaces between the front and middle and the middle and rear axles were $4.00 \mathrm{~m}$ and $1.35 \mathrm{~m}$, respectively.

\subsection{Field test results}

\subsubsection{Strain influence line identification}

Theoretical SIL is drawn at any unit on the three-span continuous beam based on the derived theoretical SIL expressions. Units $x_{1}, x_{2}$, and $x_{3}$, shown in Figure $13 \mathrm{a}$, were selected as monitoring units to present the theoretical and calibrated SILs based on the proposed method. The monitoring units were placed $15 \mathrm{~m}, 45 \mathrm{~m}$, and $39 \mathrm{~m}$ away from the adjacent left support, respectively. The dynamic response of $x_{k_{1}}, x_{k_{2}}$, and $x_{k_{3}}$ induced by the passing of the 3 -axle truck were collected by the long-gauge FBG sensors for the following analysis. The collected original strain response data were preliminarily processed using the wavelet transform method, as shown in Figure 19.

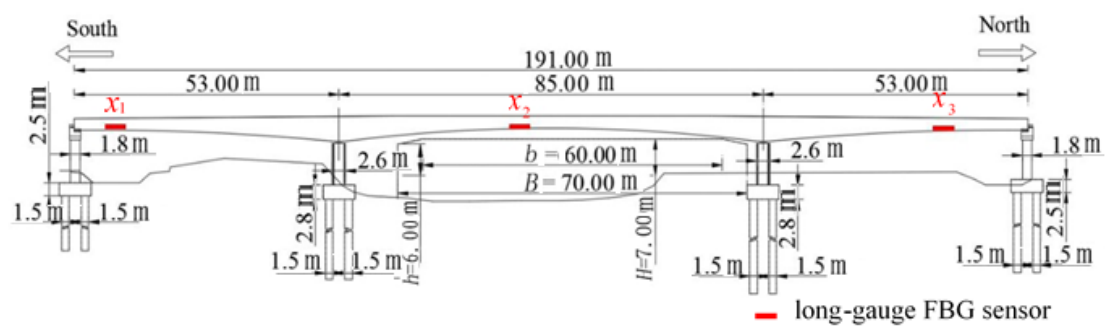

a) sensor layout

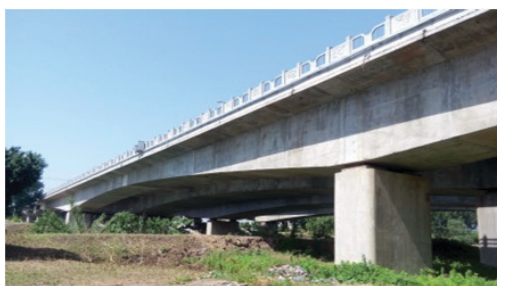

b) bridge photo

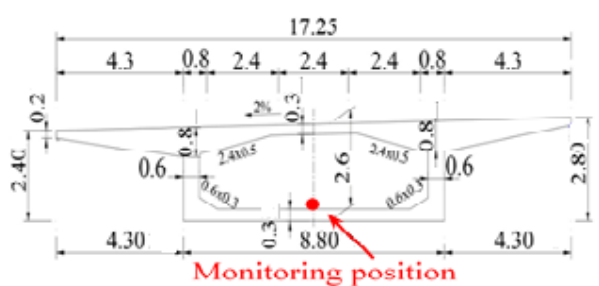

Note: units in $\mathrm{m}$.

C) typical cross-section

Figure 18. The investigated bridge and field test 
As shown in Figure 19, three extreme points are easily extracted factors of $x_{1}, x_{2}$, and $x_{3}$ were then calculated based on Equations (12), (16), and (17), respectively. The results of those calculations are shown in Figure 20.

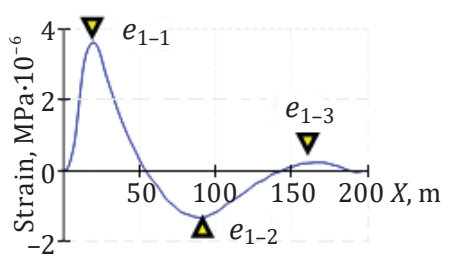

a) $x_{1}$

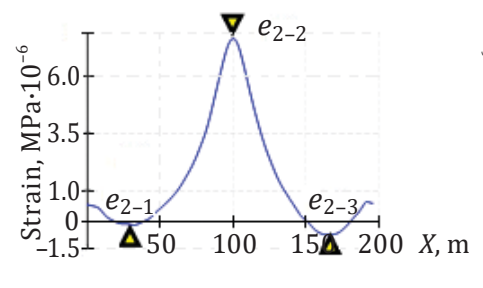

b) $x_{2}$

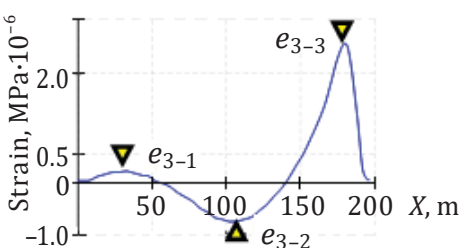

c) $x_{3}$

Figure 19. Dynamic strain responses collected by the long-gauge Fiber Bragg Grating sensors

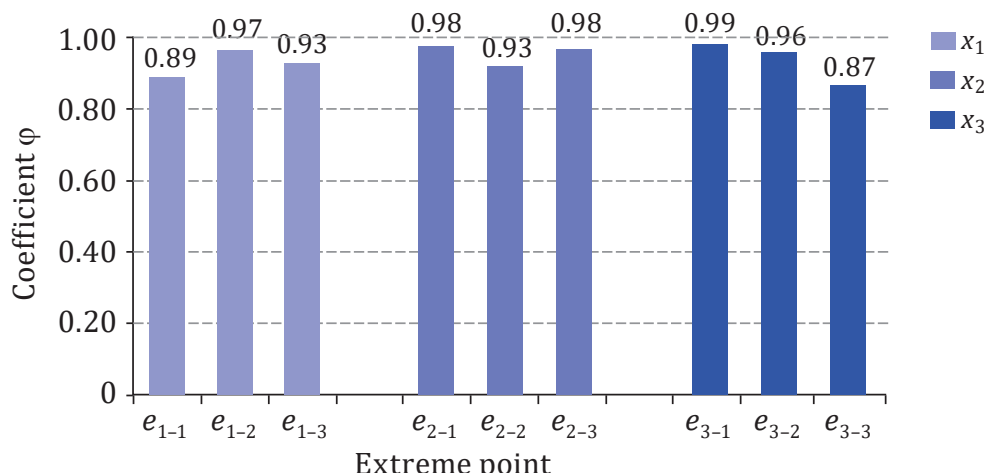

a) coefficient $\varphi$

Extreme point

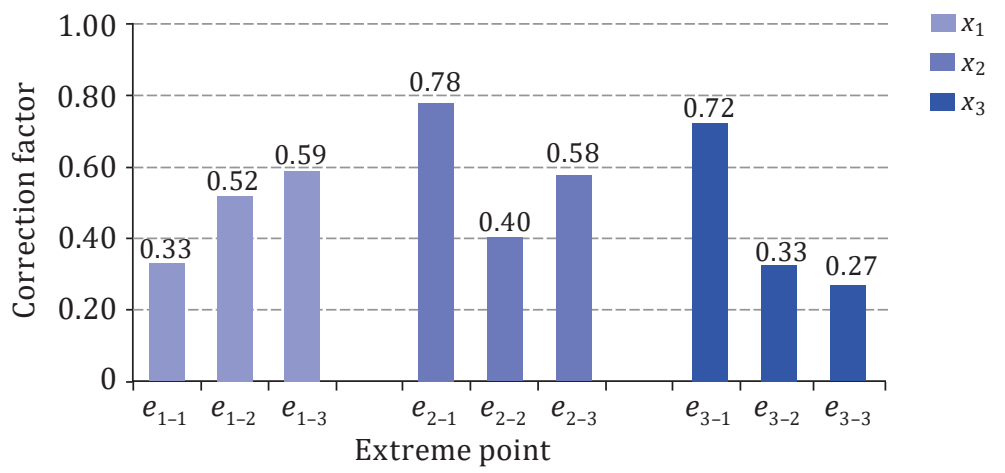

b) correction factor

Figure 20. Calculated coefficient $\varphi$ and correction factor 
THE BALTIC JOURNAL

OF ROAD

AND BRIDGE

ENGINEERING

$2021 / 16(4)$

Figure 20a presents the calculated coefficients $\varphi$ at the three units $\left(x_{1}, x_{2}\right.$, and $\left.x_{3}\right)$ using the extreme values from the collected dynamic strain time histories. It is found that the coefficients $\varphi$ of each extreme value calculated with Equations (12) and (16) are different at one monitoring unit, and the $\varphi$ of the corresponding extreme values are also different among different monitoring units. Based on the calculated coefficients $\varphi$, the correction factors were further estimated using Equation (17), as shown in Figure 20b. It is seen that the correction factors used for the calibration of the theoretical SILs are significantly different from each other, whether at the same monitoring unit or the corresponding correction factors at different monitoring units.

The theoretical SILs of the three-span continuous beam bridge was calibrated to obtain the real SILs from the in-situ measurement. The identified SILs based on Equation (18) were compared to the theoretical SILs established by Equations (2) and (3), as shown in Figure 21. For the units, $x_{1}, x_{2}$, and $x_{3}$, the maximum values of the identified SILs are much smaller than the theoretical SILs. The absolute values of other extreme values of the identified SILs are also smaller than the corresponding absolute values of the theoretical SILs. However, the difference among these extreme values is slight. It is easy to find from Figure 21 that there is a particular deviation between the actual state and the ideal state of the investigated bridge due to design parameter error, construction error and measurement error.

\subsubsection{Strain influence line verification}

In the field testing, two kinds of tests were conducted to verify the identified SILs based on the proposed method in this paper. One truck was adopted for the case I, in which a pre-weighed truck with a gross weight of $30 \mathrm{t}(300 \mathrm{kN})$ crossed over the continuous girder bridge with a low speed of approximately $5 \mathrm{~km} / \mathrm{h}$. In case II, two trucks passed at
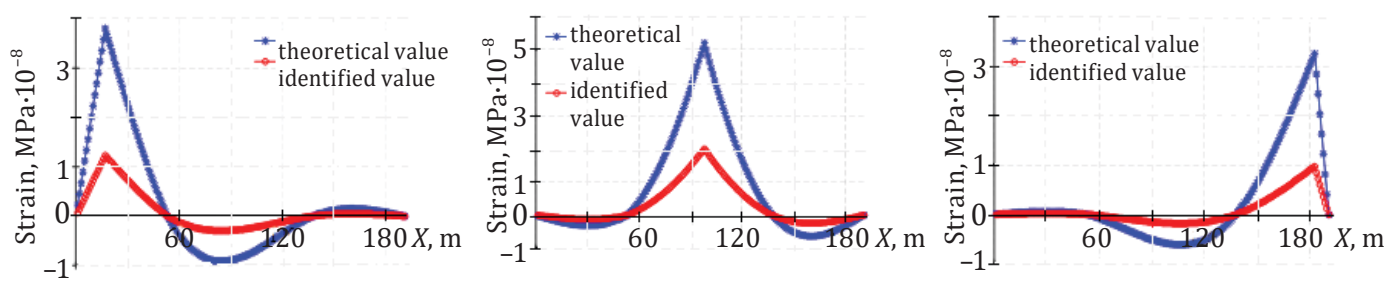

a) $x_{1}$

b) $x_{2}$

c) $x_{3}$

Figure 21. Identified strain influence lines using the measured strain 
the same lane of the investigated bridge with different speeds, which had the exact vehicle parameters with the truck used in case I. The SILs identified in Section 4.2.1. were further used to simulate the dynamic strain response under two cases and compare it with the measured strain time history data, as shown in Figure 22. Figures 22a and 22b show the strain response curves of $x_{2}$, and $x_{3}$ in case I, while Figures $22 \mathrm{c}$ and $22 \mathrm{~d}$ represent the strain response curves of $x_{2}$, and $x_{3}$ in case II derived from the identified SILs. It is seen from Figures $22 \mathrm{a}$ and $22 \mathrm{~b}$, the strain response in case I simulated by the identified SILs coincides with the measured response. Although the test trucks in case II were required to pass across the bridge at a constant speed, human factors still led to some non-uniform velocity, so there are some inconsistencies in Figures $22 \mathrm{c}$ and $22 \mathrm{~d}$. Nevertheless, on the whole, the simulated dynamic strain response curves are consistent with the measured strain curve. Thus, it is concluded that the proposed method accurately extracts the real continuous beam bridge SILs from the dynamic response.

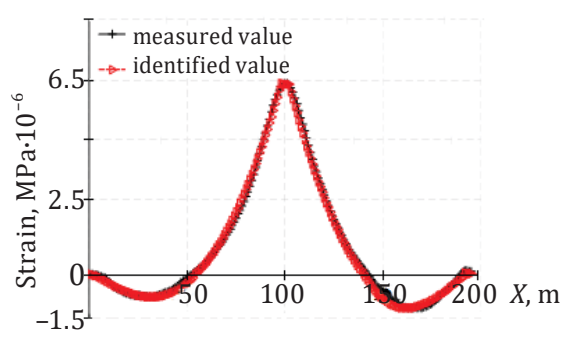

a) $x_{2}$ - case 1
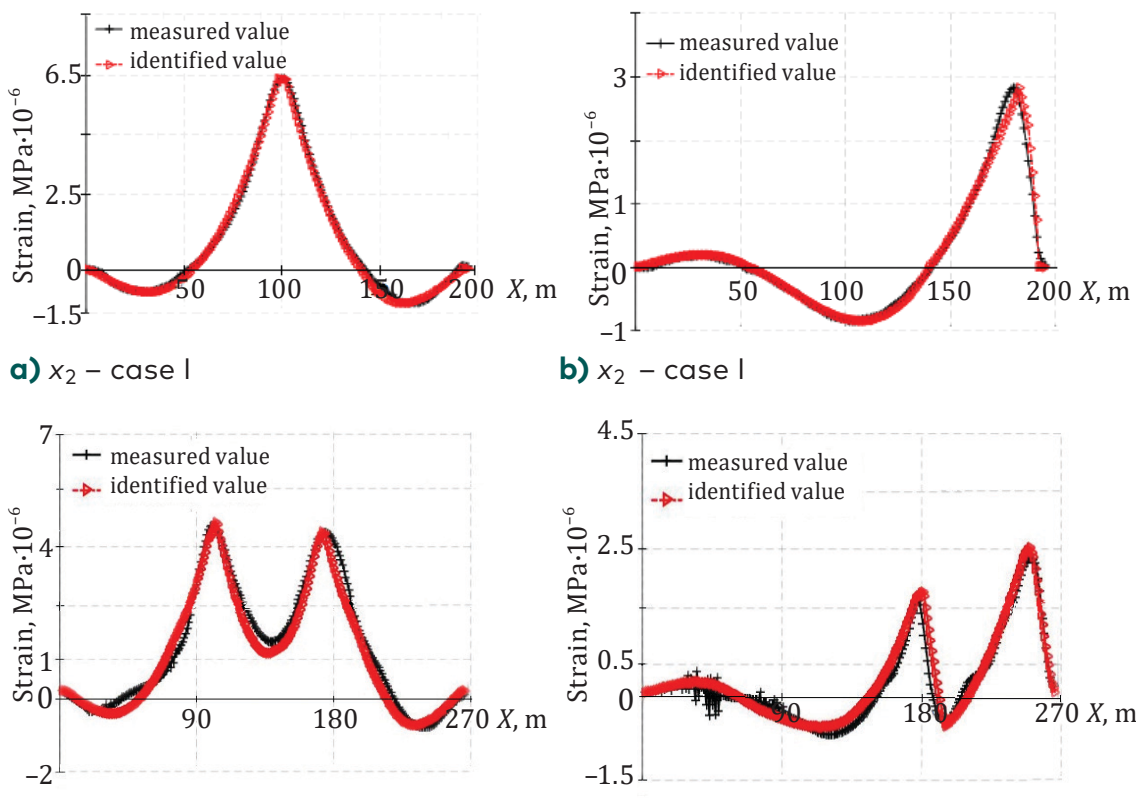

b) $x_{2}$ - case I

c) $x_{2}$ - case II

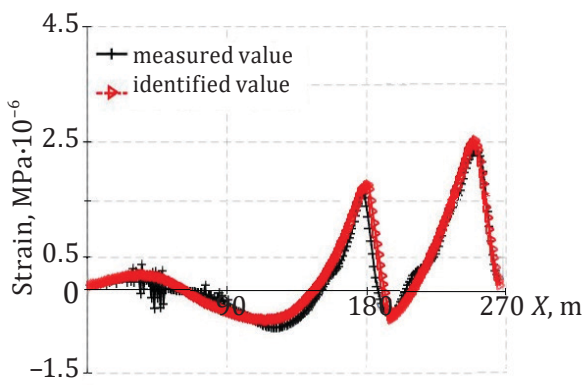

d) $x_{3}-$ case II
Eliminating the Influence of Axle Parameters in Influence Line Identification

Figure 22. Estimated strain time history by the identified strain influence lines 
THE BALTIC JOURNAL

OF ROAD

AND BRIDGE

ENGINEERING

2021/16(4)

\section{Conclusions}

This paper introduces an innovative identification method of strain influence line by estimating the influence of vehicle parameters on strain responding to obtain the real strain influence line of the investigated continuous beam bridge. The mathematical equations to calculate the strain influence lines considering a transverse lane distribution are presented. strain influence lines

The numerical simulation and field test verified the proposed algorithm. The numerical simulation verified that the vehicle parameters have a particular influence on the strain response. It also discusses the influence of different vehicle speeds on the strain response and additional lane testing. In addition, the field test of the three-span continuous beam bridge was carried out to test and evaluate the accuracy of the proposed method in the strain influence lines identification compared with the algorithm ignoring the axle parameters. The main conclusions of this study are summarised as follows:

1. The proposed method is effective in calculating strain influence lines and applied as a reference for strain influence line identification of continuous beam bridge.

2. Estimation method of strain influence line is researched under different lane distribution. For the monitoring unit with a facing lane, the strain influence line is identified directly using the test of the facing lane. However, for the monitoring unit without a facing lane, the strain influence line needs to be calculated using the tests of two adjacent lanes nearby. Additional transverse lane testing has been verified in the numerical simulation but fails in field tests due to a lack of data. The actual bridge verification for additional lane testing is expected to be completed in future research.

3. Several numerical simulation examples validate that the proposed method accurately obtains the strain influence lines from dynamic responses. This paper discusses the influence of axle spacing and axle weight ratio on the structural response. The results prove that the axle weights, spacing, and axle weight ratio affect the structural response. It also verifies that the proposed method effectively eliminates the effect of these axle parameters on strain influence line identification. Simulation results show that higher speeds cause fluctuations only near the extreme values and have little effect on the identified strain influence lines, proving the proposed method's robustness. The field test also shows that the proposed method is capable of accurately obtaining the real strain influence lines of continuous beam bridges from the dynamic response. 


\section{Data availability}

The data used to support the findings of this study are available from the corresponding author upon request.

\section{Acknowledgements}

This research was supported by the National Natural Science Foundation of China (Grant No. 51908386). It was also supported by the Science and Technology Funds for the Communications Department of Jiangxi Province, China (Grant No. 2017C0002).

\section{REFERENCES}

Bao, T., Babanajad, S. K., Taylor, T., \& Ansari, F. (2016). Generalised method and monitoring technique for shear-strain-based bridge weigh-in-motion. Journal of Bridge Engineering, 21(1), 04015029.

https://doi.org/10.1061/(ASCE)BE.1943-5592.0000782

Casas, J. R., \& Cruz, P. J. (2003). Fiber optic sensors for bridge monitoring. Journal of Bridge Engineering, 8(6), 362-373.

https://doi.org/ 10.1061/(ASCE)1084-0702(2003)8:6(362)

Chen, Z. W., Cai, Q. L., \& Li, J. (2016). Stress influences line identification of long suspension bridges installed with structural health monitoring systems. International Journal of Structural Stability \& Dynamics, 16(04), 1640023. https://doi.org/10.1142/S021945541640023X

Chen, Z. W., Zhu, S., Xu, Y. L., Li, Q., \& Cai, Q. L. (2015). Damage detection in long suspension bridges using stress influence lines. Journal of Bridge Engineering, 20(3), 05014013.

https://doi.org/10.1061/(ASCE)BE.1943-5592.0000681

Chen, Z., Yang, W., Li, J., Cheng, Q., \& Cai, Q. (2017). A systematic method from influence line identification to damage detection: Application to RC bridges.

Computers \& Concrete, 20(5), 563-572.

https://doi.org/10.12989/cac.2017.20.5.563

Chen, Z., Yang, W., Li, J., Yi, T., Wu, J., \& Wang, D. (2019). Bridge influence line identification based on adaptive B-spline basis dictionary and sparse regularisation. Structural Control \& Health Monitoring, 26(6), e2355.

https://doi.org/10.1002/stc.2355

Frøseth, G. T., Rønnquist, A., Cantero, D., \& Øiseth, O. (2017). Influence line extraction by deconvolution in the frequency domain. Computers \& Structures, 189, 21-30. https://doi.org/10.1016/j.compstruc.2017.04.014

Heitner, B., Schoefs, F., OBrien, E. J., Žnidarič, A., \& Yalamas, T. (2020). Using the unit influence line of a bridge to track changes in its condition. Journal of Civil Structural Health Monitoring, 10(4), 667-678.

https://doi.org/10.1007/s13349-020-00410-7
Eliminating the Influence of Axle Parameters in Influence Line Identification 
THE BALTIC JOURNAL OF ROAD AND BRIDGE ENGINEERING 2021/16(4)

Hirachan, J., \& Chajes, M. (2005). Experimental influence lines for bridge evaluation. Bridge Structures, Assessment, Design \& Construction, 1(4), 405-412. https://doi.org/10.1080/15732480600578485

Hosur, V., \& Bhavikatti, S. S. (1996). Influence lines for bending moments in beams on elastic foundations. Computers \& Structures, 58(6), 1225-1231. https://doi.org/10.1016/0045-7949(95)00219-7

Ieng, S. S. (2015). Bridge influence line estimation for bridge weigh-in-motion system. Journal of Computing in Civil Engineering, 29(1), 06014006. https://doi.org/ 10.1061/(ASCE)CP.1943-5487.0000384

Inaudi, D. (2001, August). Application of optical fiber sensor in civil structural monitoring. In Smart Structures \& Materials 2001: Sensory Phenomena \& Measurement Instrumentation for Smart Structures \& Materials (Vol. 4328, pp. 1-10). International Society for Optics and Photonics. https://doi.org/ 10.1117/12.435512

Li, S., \& Wu, Z. (2007). Development of distributed long-gage fiber optic sensing system for structural health monitoring. Structural Health Monitoring, 6(2), 133-143. https://doi.org/10.1177/1475921706072078

Liu, F. (2019). Bridge health status evaluation based on influence line. Modern Transportation Technology, 16(3), 41-45. (in Chinese)

McNulty, P., \& O’Brien, E. J. (2003). Testing of bridge weigh-in-motion system in a sub-Arctic climate. Journal of Testing \& Evaluation, 31(6), 497-506. https://doi.org/10.1520/JTE12377J

OBrien, E. J., Quilligan, M. J., \& Karoumi, R. (2006, March). Calculating an influence line from direct measurements. In Proceedings of the Institution of Civil Engineers-Bridge Engineering (Vol. 159, No. 1, pp. 31-34). Thomas Telford Ltd. https://10.1680/bren.2006.159.1.31

Schulz, W. L., Conte, J. P., \& Udd, E. (2001, July). Long-gage fiber optic Bragg grating strain sensors to monitor civil structures. In Smart Structures \& Materials 2001: Smart Systems for Bridges, Structures, \& Highways (Vol. 4330, pp. 56-65). International Society for Optics and Photonics. https://doi.org/10.1117/12.434156

Sohn, H., Farrar, C. R., Hemez, F. M., Shunk, D. D., Stinemates, D. W., Nadler, B. R., \& Czarnecki, J. J. (2003). A review of structural health monitoring literature: 1996-2001. Los Alamos National Laboratory, USA, 1.

Štimac, G. I., Grandić, D., \& Bjelanović, A. (2011). Comparison of techniques for damage identification based on influence line approach. VIII International Congress: Machines, Technologies, Materials, Italy, 7, 9-13.

Strauss, A., Wendner, R., Frangopol, D. M., \& Bergmeister, K. (2012). Influence line-model correction approach for the assessment of engineering structures using novel monitoring techniques. Smart Structures \& Systems, 9(1), 1-20. https://doi.org/10.12989/sss.2012.9.1.001

Wang, L., Zhou, Y., Di, S., \& Xiang, C. (2020). Influence line Analysis and Damage Detection of Railway Bridge Deflection with Non-ideal Boundaries. Advanced Engineering Sciences, 52(03), 123-132. https://doi.org/10.15961/j.jsuese.201900316. (in Chinese) 
Wang, N. B., He, L. X., Ren, W. X., \& Huang, T. L. (2017). Extraction of influence line through a fitting method from bridge dynamic response induced by a passing vehicle. Engineering Structures, 151, 648-664. https://doi.org/10.1016/j.engstruct.2017.06.067

Wang, Y., \& Qu, W. L. (2011). Moving train loads identification on a continuous steel truss girder by using dynamic displacement influence line method. International Journal of Steel Structures, 11(2), 109-115. https://doi.org/10.1007/s13296-011-2001-7

Xu, W., Zhang, J., \& Wei, X. (2015). Research on dynamic influence line of bridge under random vibration of vehicle and bridge. Applied Mathematics \& Mechanics, 36(09), 914-923. (in Chinese)

Zhang, Q., Zhang, J., Duan, W., \& Wu, Z. (2018). Deflection distribution estimation of tied-arch bridges using long-gauge strain measurements. Structural Control \& Health Monitoring, 25(3), e2119. https://doi.org/ 10.1002/stc.2119

Zhao, H., Uddin, N., O'Brien, E. J., Shao, X., \& Zhu, P. (2014). Identification of vehicular axle weights with a bridge weigh-in-motion system considering transverse distribution of wheel loads. Journal of Bridge Engineering, 19(3), 04013008. https://doi.org/10.1061/(ASCE)BE.1943-5592.0000533

Zhao, H., Uddin, N., Shao, X., Zhu, P., \& Tan, C. (2015). Field-calibrated influence lines for improved axle weight identification with a bridge weigh-in-motion system. Structure \& Infrastructure Engineering, 11(6), 721-743. https://doi.org/10.1080/15732479.2014.904383

Zhao, Z., Uddin, N., \& O'Brien, E. J. (2017). Bridge weigh-in-motion algorithms based on the field calibrated simulation model. Journal of Infrastructure Systems, 23(1), 04016021. https://doi.org/10.1061/(ASCE)IS.1943-555X.0000308

Zheng, X., Yang, D. H., Yi, T. H., \& Li, H. N. (2019a). Development of bridge influence line identification methods based on direct measurement data: a comprehensive review and comparison. Engineering Structures, 198, 109539. https://doi.org/10.1016/j.engstruct.2019.109539

Zheng, X., Yang, D. H., Yi, T. H., \& Li, H. N. (2020). Bridge influence line identification from structural dynamic responses induced by a high-speed vehicle. Structural Control \& Health Monitoring, 27(7), e2544.

https://doi.org/10.1002/stc.2544

Zheng, X., Yang, D. H., Yi, T. H., Li, H. N., \& Chen, Z. W. (2019b). Bridge influence line identification based on regularised least-squares QR decomposition method. Journal of Bridge Engineering, 24(8), 06019004. https://doi.org/10.1061/(ASCE)BE.1943-5592.0001458

Zhou, Y., Zhou, S., Pei, Y., Cheng, Y., \& Li, Z. (2020). A non-contact identification of bridge influence line based on big data using interval analysis and affine algorithm. Earthquake Engineering \& Engineering Dynamics, 40(3):20-31. https://doi.org/10.13197/j.eeev.2020.03.20.zhouy.003 (in Chinese)

Znidaric, A., \& Baumgartner, W. (1998). Bridge weigh-in-motion systems - an overview. In Second European Conference on Weigh-in-Motion of Road Vehicles, held Lisbon, Portugal 14-16 September 1998.
Qingqing Zhang, 